\title{
Meia-Noite em Paris. Na hora aberta da meia-noite: o cinema, as artes e a sedução da Modernidade.
}

\author{
Maria Ignês Carlos Magno \\ Doutora em Ciências da Comunicação pela ECA/USP. Professora do mestrado em \\ Comunicação da Universidade Anhembi Morumbi e da Fundação Escola de Sociologia e \\ Política de São Paulo. \\ E-mail: unsigster@gmail.com
}

Resumo: A autora faz uma análise do filme Meia-noite em Paris (Midnight in Paris), comédia dramática cujo roteiro e direção foram conduzidos por Wood Allen, em 2011, que retoma o realismo mágico de outros filmes e mostra em sua obra um pouco sobre uma das épocas históricas que marcaram muitas gerações pela força dos movimentos artísticos e revolucionários: o início do século XX em Paris. A sedução que a cidade, suas luzes e sua modernidade exerceram e continuam a exercer sobre intelectuais e artistas de várias partes do mundo.

Palavras-chave: Hora aberta; cinema; anos 1920; Paris; vanguardas modernistas.
Abstract: The author analyses the movie Midnight in Paris, a comedy written and directed by Woody Allen in 2011, which returns to the magical realism from his other movies and shows part of historical times that have determined many generations with the power of artistic and revolutionary movements: the early $20^{\text {th }}$ century in Paris. The seduction that the city, its lights and its modernity have exerted and continue exerting over academicians and artists around the world.

Keywords: Open hour; Cinema; 20's; Paris; Modernist vanguards.

As horas abertas são quatro: meio-dia, meia-noite, anoitecer e amanhecer.

São as horas em que se morre, em que se piora, em que os feitiços agem fortemente, em que as pragas e as súplicas ganham expansões

maiores. Horas sem defesa [...]. Na ambivalência natural, meio-noite e meio-dia prestam-se às rogativas benéficas, mas constituem exceção. (Luis da Câmara Cascudo). 
comunicação \& educação • Ano XV|II • número 1 • jan/jun 2013

No florescimento do Segundo Império, as lojas não fecham antes das dez horas da noite. Era a grande época do noctambulismo.

"O ser humano" - escreve Delvau no capítulo de As Horas Parisienses, dedicado à segunda hora depois da meia-noite - "pode de tempos em tempos repousar; pontos de parada e estações lhe são franqueadas; não tem, contudo, o direito de dormir".

(Walter Benjamin)

\section{INTRODUÇÃO}

Muito foi dito e escrito sobre o filme Meia-Noite em Paris (2012), de Woody Allen. Não apenas a crítica especializada se ocupou de análises e interpretações sobre o filme, mas todos aqueles que aprenderam a gostar de cinema, e também os que não estão muito preocupados se as personagens são sempre o alter

Kathy Bates Adrien Brody Carla Bruni Marion Cotillard Rachel McAdams Michael Sheen Owen Wilson

\section{Meia Noite em Paris}

Escrito e Dirigido por Woody Allen

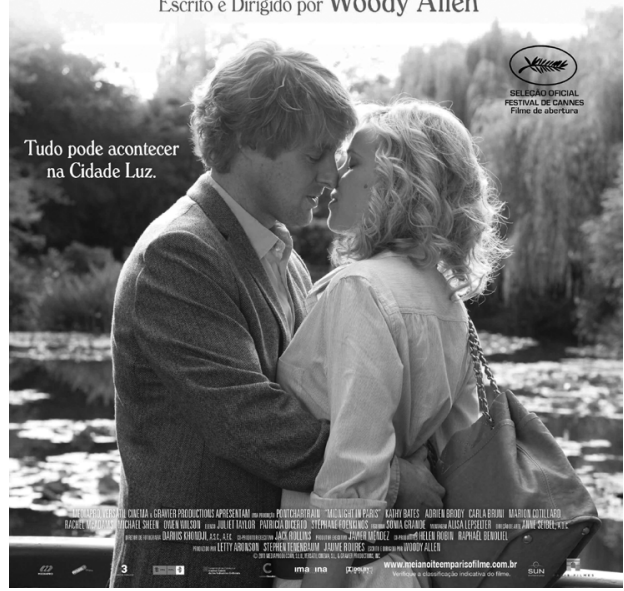

Reprodução de cartaz de divulgação do filme. ego do diretor; se ele estava inspirado ou não. Ou, ainda, se conta sempre a mesma história.

Não importa, porque o que interessa é assistir a um filme que tem uma história bem contada. E isso Allen sabe fazer. Por último, se o diretor retoma nesse filme o realismo mágico de outros filmes, ótimo, porque podemos, como a personagem Gil, pegar carona na hora aberta da meia-noite em Paris e conhecer um pouco sobre uma das épocas históricas que marcaram muitas gerações pela força dos movimentos artísticos e revolucionários: o início do século XX. Particularmente Paris e a sedução que a cidade, suas luzes e sua modernidade exerceram e continuam a exercer sobre intelectuais e artistas de várias partes do mundo.

\section{DA HISTÓRIA DO FILME ÀS HISTÓRIAS DOS MOVIMENTOS ARTÍSTICOS DO INÍCIO DO SÉCULO XX}

Meia-Noite em Paris conta a história de Gil Pender, um roteirista de Hollywood apaixonado pelos grandes escritores norte-americanos e que queria, como eles, escrever um grande romance. Gil Pender vai a Paris ao lado de sua noiva e dos pais dela. Os pais de Inez vão fechar um grande negócio na cidade. Estar em 
Paris faz com que Gil volte a questionar sua vida e desejar realizar o sonho de se tornar um escritor renomado. Ao perambular pelas ruas parisienses tentando encontrar o caminho de volta para o hotel, na hora aberta da meia-noite Gil entra em um carro que o leva para uma festa na Paris do início do século XX. Na festa organizada pelo poeta, dramaturgo, cineasta Jean Cocteau, Gil começa viver um duplo sonho: o de conviver com seus ídolos e ter a chance de se tornar um escritor. E as primeiras perguntas podem ser feitas: Por que Paris e não qualquer outra cidade da Europa? Por que Paris foi a cidade que todos os expoentes da intelectualidade na época escolheram para visitar, viver, produzir, estudar ou entender o porquê do fascínio daquela cidade?

Para começar a responder a essas perguntas, podemos retomar um dos últimos passeios de Gil na Paris dos anos vinte: o jantar com Adriana no restaurante Maxim's e, depois, o Cabaré Moulin Rouge, que é quando se encontram e conversam com Henri de Toulouse-Lautrec e, em seguida, com Paul Gauguin e Edgar Degas.

Como uma de nossas propostas é a de recuperar os movimentos artísticos dos anos 1920, creio que podemos começar pelo final, porque esses pintores, juntamente com outros que não aparecem no filme, não só participaram da atmosfera daqueles anos como deram as bases de outros movimentos do século XX. E, como esses artistas pertenceram aos movimentos conhecidos como neoimpressionismo e expressionismo, a sugestão é a de iniciar os estudos pelo impressionismo.

Embora saibamos que nenhum movimento artístico é homogêneo, é interessante perceber as características norteadoras, as ramificações ou os desdobramentos que caracterizam cada um deles. É o caso do neoimpressionismo e do expressionismo, que tiveram suas bases na proposta impressionista. Em Paris (1905), o neoimpressionismo e, em Dresden (1905), o expressionismo. Paul Cèzanne, Vincent Van Gogh, Paul Gauguin, Henri Matisse e Henri de Toulouse-Lautrec, entre outros, sem abandonar os pressupostos impressionistas, mas na tentativa de alargar os horizontes daquela proposta, investiram não só no estudo da luz e da cor através de estudos científicos, como assumiram uma pintura que tinha como uma de suas características as distorções das formas que expressavam o mundo hostil. A arte entendida como a arte do instinto, uma pintura dramática em que os sentimentos humanos eram ressaltados mesmo que a figura humana fosse deformada. Especialmente o expressionismo deve ser estudado em sua totalidade, já que aparece com força em dois momentos da história: 1905 e 1930.

Iniciar os estudos por esses movimentos nos interessa porque em 1905, também no Salão de Outono de Paris, surge um movimento que é considerado o primeiro grupo da vanguarda europeia: o fauvismo, de Fauve (feras). Nome ironicamente cunhado por um crítico de arte, esse movimento, embora com vida curta (1905/1908), teve como representantes: André Duran e Georges Braque, de quem Pablo Picasso sofre uma grande influência. Já que todas as personagens que aparecem no filme ou fizeram parte direta da vanguarda, ou 
comunicação \& educação • Ano XV|l| • número 1 • jan/jun 2013

transitaram e conviveram com os ideários e propostas desse movimento, que foi um dos mais importantes do século XX, ele merece um estudo aprofundado.

\section{PARIS E AS VANGUARDAS DOS ANOS 1920}

A vanguarda pode ser entendida como uma multiplicidade de tendências artísticas e culturais preocupadas com uma visão e interpretação da realidade. Pode ser considerada como uma grande síntese artística da Europa do início do século XX, seja como reação ao desenvolvimento tecnológico e científico e aos progressos da Revolução Industrial, seja como reação às assimetrias sociais e projetos ideológicos e políticos que levaram a um conflito em escala planetária, a Primeira Guerra Mundial, ou mesmo como síntese de correntes artísticas que proclamavam a liberdade e a criação de um novo estilo de arte.

Nessa perspectiva, a pesquisa dos demais movimentos que afloraram nesse período pode ser continuada, bem como ampliada para além das características próprias dos movimentos: as relações que mantinham entre si e com os acontecimentos históricos daqueles anos. Um deles: a Primeira Guerra (1914-1918).

Considerando a simultaneidade dos movimentos e, ao mesmo tempo, a didática, uma linearidade será mantida para efeitos de pesquisa e entendimento. Nessa perspectiva, o cubismo (1907-1914) e o futurismo italiano (1909-1916) são os próximos movimentos do período a serem estudados. O cubismo, com o célebre quadro de Picasso "Les Demoiselles d'Ávignon", marca a crise do fauvismo. Para os cubistas, um quadro é uma estrutura autônoma, que não representa a realidade, mas é uma realidade própria. Inspirado nas artes africanas, na racionalidade e no "princípio de realização" de Cèzanne, terá como uma de suas características a geometrização das formas, na expressão visual da luz e da sombra, rompendo com a ideia de que a arte é uma imitação da natureza. Além de Braque e Picassso, outros artistas ligados a esse movimento foram: Guillaume Apollinaire, Max Jacob, Francis Picabia, Fernand Lèger e Marchel Duchamp.

Entre 1914 e 1918 muitos jovens são enviados para a frente dos campos de batalha. Em 1909 Felippo de Tomanaso Marinetti lança o 1o Manifesto Futurista. Esse movimento conclama o fim da arte passada em rumo ao futuro e mostra suas implicações políticas. Ao todo foram quatro manifestos. Depois do 1o Manifesto em 1909, em 1910, é lançado o Manifesto da Pintura, em 1912, o Manifesto da Escultura e, em 1914, surge um livro onde se expressa que deve ser feita uma limpeza radical em todos os gostos mofados, a fim de mostrar o vórtice da vida moderna: a vida do aço, da febre, do orgulho e da velocidade. Em 1916, um dos líderes do futurismo italiano, Umberto Boccione, morre, vítima de ferimentos da guerra, e o movimento começa a entrar em decadência.

Embora os dadaístas não tenham feito parte da história do filme nem transitado pela casa de Gertrude Stein, com exceção de Man Ray e Francis Picabia, o movimento dadaísta, que nasceu em plena guerra, em 1915, em 
Meia-Noite em Paris. Na hora aberta da meia-noite - Maria Ignês Carlos Magno

Zurique, teve um significado tão forte quanto a guerra. Com base na filosofia anarquista e no niilismo, negava todas as tradições sociais e artísticas da época, pregava o slogan de Bakunin: "a destruição também é um ato de criação", tinha por objetivo o choque e o escândalo. Mas não só, os dadaístas reuniam-se no Cabaret Voltaire e pretendiam criar uma arte internacional com apresentações de música, poesia, exposições de arte.

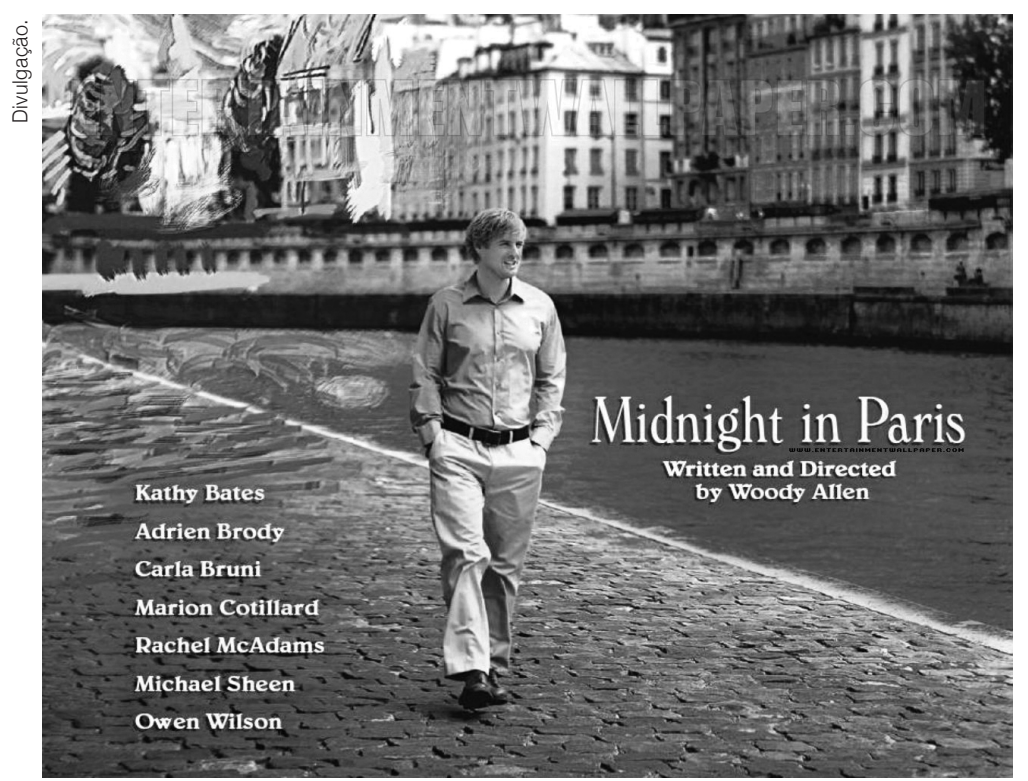

Em 1917 lançam: Cabaret Voltaire, Galeria Dadá e a Revista Dadá. Seus criadores e principais representantes foram: Tristan Tzara, Hans Harp, Hugo Ball, Hans Richter, Michel Duchamp. Francis Picabia, que transitou do cubismo ao dadaísmo, acabou fazendo uma ponte entre o dadaísmo europeu e norte-americano. Vale a pena conhecer tanto a produção desses artistas como aprofundar as linhas gerais aqui expostas. Principalmente porque as propostas dadaístas serviram de inspiração para o movimento surrealista, em 1924.

O Manifesto Surrealista, de André Breton, marca historicamente o surgimento do movimento. Nele se propunha, entre outras propostas, a restauração dos sentimentos humanos. As incertezas políticas do pós-guerra colaboraram para o surgimento de uma arte crítica. Breton reuniu em torno de si artistas ligados a uma filosofia de pensamento e ação, em que a liberdade era valorizada. Tinham como proposta um forte apelo às imagens na descrição de aspectos do subconsciente.

O caráter antirracionalista do movimento vai na direção contrária das tendências construtivistas e do projeto de retorno à ordem surgidos após a Primeira Guerra. Em 1925 eles lançam a Revista Revolucion Surrealiste, afinam a arte com a política e anunciam a adesão do movimento ao comunismo. Nem todos os participantes do grupo aderem a essa ligação. 


$$
\text { comunicação \& educação • Ano XVIII • número } 1 \text { • jan/jun } 2013
$$

O movimento mobiliza quase todas as tendências artísticas como a pintura, a literatura, a fotografia, as artes gráficas e o cinema. Alguns dos representantes foram: André Breton, Louis Aragon, Georges Bataille, Max Jacob, entre outros, que se destacaram na literatura; René Magritte, Max Ernest, André Masson e Salvador Dalí, na pintura. Man Ray e Dora Maar, na fotografia, e Luís Buñel, no cinema.

Outro aspecto que interessa saber é a sua difusão tanto na Europa como nos Estados Unidos e América Latina. Particularmente no Brasil, vale estudar a produção de Ismael Nery, Cícero Dias e Jorge de Lima.

\section{A VANGUARDISTA GERTRUDE STEIN, A LIVRARIA SHAKESPEARE \& CIA E A "GERAÇÃO PERDIDA" NA FICÇÃO DE WOOD ALLEN}

Gertrude Stein era poeta e escritora vanguardista. Norte-americana de origem, vivia em Paris cuidando do valioso acervo da família. Sua casa na Rue de Fleurus, n. 27, descrita no livro autobiográfico de sua companheira Alice Bebette Toklas, era exatamente como aparece no filme de Allen: um minúsculo pavilhão de dois andares com quatro pecinhas, cozinha e banheiro, e um vasto ateliê anexo. Sua casa era um ponto de encontro de toda uma geração de poetas, escritores, pintores, que ela denominou "geração perdida". Mentora de jovens escritores e artistas, congregava ao seu redor um círculo de artistas formado por Pablo Picasso, Henri Matisse, Georges Braque, André Darain, Juan Gris, Guillame Apollinaire, Francis Picabia, Ezra Pound, Ernest Hemingway, James Joyce, apenas para citar alguns dos nomes que compõem a história do filme e personagens com quem Gil convive e dialoga sempre que entra na hora aberta da meia-noite em Paris.

Além deles, na Paris da ficção de Allen, outros escritores e artistas marcaram presença, como o casal de escritores Zelda e Scott Fitzgerald, o poeta Thomas S. Eliot, Josephine Baker, a famosa atriz, cantora e dançarina americana conhecida como "Vênus Negra", e Cole Porter, músico. Aliás, é Cole Porter quem estava tocando piano na festa para onde Gil Pender foi levado no início do filme. Cantava a música que simbolizou o período em que morou em Paris: Let's do it.

Nessa jornada de Woody Allen sobre a cidade de Paris nos anos loucos, outro ícone do período é trazido no filme: a lendária Livraria Shakespeare \& Cia, fundada em 1919 pela livreira Silvia Beach. Na época localizada na Rive Gauche, onde se reuniam Hamingway, Ezra Pound, James Joyce, Ford Madox Ford, o casal Fitzgerald, Man Ray e a própria Gertrude Stein. A importância dessa livraria, além do fato de ser ponto de encontro dessa geração vanguardista, está também no fato de a livreira Silvia Beach ter editado o livro Ulisses, de James Joyce, em 1922, que na época fora recusado por todos os editores de Paris. Hoje um dos clássicos da literatura universal. E essa pode ser outra parte da pesquisa: a literatura vanguardista produzida no período. 
Penso que, se bem conduzidas, essas pesquisas e discussões serão de grande valor e prazer para essa nova geração altamente linkada e com todas as informações disponíveis, mas um pouco carente da leitura de um belo conto, de uma poesia lida em voz alta, ou em silêncio mesmo, de histórias de outras gerações.

Se prestada a devida atenção, os professores poderão se surpreender ao verem como, mesmo nos dias atuais, uma boa história pode deixar uma plateia em silêncio. Allen soube contar em imagens e textos uma boa história como essa Meia-noite da Paris-sedução, das luzes, das vanguardas modernistas, da efervescência da cidade-luz dos anos 1920.

Pensando bem, cabem duas perguntas para finalizar essa proposta de trabalho: James Joyce era difícil para uma geração acostumada com a leitura linear. Será para essa? Ou, se ainda for difícil, por que não a leitura de Charles Baudelaire para conhecermos a outra Paris descrita em seus poemas e prosas?

Ficha técnica

Título: Meia-noite em Paris. (Midnight in Paris)

Roteiro e direção: Wood Allen

Gênero: comédia dramática

Fotografia: Darius Khondji

Trilha sonora: Stephane Wrembel

Duração: 95 min.

Ano: 2011.

\section{REFERÊNCIAS BIBLIOGRÁFICAS}

BENJAMIN, Walter. Charles Baudelaire: um lírico no auge do capitalismo. São Paulo: Brasiliense, 1989, p. 47.

DA CÂMARA CASCUDO, Luis. Coisas que o povo diz. São Paulo: Global, 2009, p. 49,50 . 